\title{
Exploration of Correlations between Factors Influencing Communication in Complex Product Development
}

\author{
Anja M. Maier, ${ }^{1, *}$ Matthias Kreimeyer, ${ }^{2}$ Clemens Hepperle, ${ }^{2}$ Claudia M. Eckert, ${ }^{1}$ \\ Udo Lindemann ${ }^{2}$ and P. John Clarkson ${ }^{1}$ \\ ${ }^{1}$ Engineering Design Centre, University of Cambridge, England \\ ${ }^{2}$ Technical University of Munich, Institute of Product Developement, Germany
}

\begin{abstract}
Designing complex products, such as jet engines, cars or certain types of software, necessitates the coordination of activities of many participants during the design process. Communication is seen as the vehicle by which this coordination could be achieved. Communication itself is influenced by many different factors that are connected. This study presents an exploration of correlations between these factors based on statistical analyses of empirical data. The research uses data collected via the 'Communication Grid Method', (CGM) a structured maturity grid method to assess the perception of communication within and across team-interfaces. Five empirical studies in the aerospace, automotive, and IT industries where concurrent engineering is practiced are used. The results offer insights for researching and managing communication across inter-departmental interfaces. It has been shown in particular, how directly and indirectly linked factors influencing communication in product development form a network of correlations. Mutual trust and collaboration exhibit thematic centrality.
\end{abstract}

Key Words: communication, concurrent engineering, research and development management, product development organizations, case studies in industry, collaboration, maturity grid.

\section{Introduction}

Products and services result from interactions among a multitude of people who work across functional, organizational, cultural, temporal, and geographical boundaries [1,2]. In concurrent engineering, tasks are distributed among individuals and whenever possible executed in parallel, increasing the need for effective communication. Concurrent collaborative design processes are challenging because strong interdependencies between design decisions make it difficult to converge on a single design solution that satisfies these dependencies and is acceptable to all participants [3]. Typically, the different participants in the design process possess different competences, skills, responsibilities, interests, and inhabit different 'object-worlds' [4]. Everyone has different 'viewpoints' [5] which can lead to conflicts that need to be resolved through negotiations [4]. For example, the early phases of designing the body of a car require bringing together car styling and core engineering. Core engineering encompasses, For example, the product's performance and properties, such as stiffness or crashworthiness as well as manufacturability [6]. In particular, collaboration between

*Author to whom correspondence should be addressed. E-mail:am521@cam.ac.uk embodiment design (CAD) and simulation departments (CAE) is a key element to a highly efficient design process $[7,8]$.

To illustrate, in automotive sheet metal design, a number of welding spots need to be specified. At a particular German automotive manufacturer, the welding spots are designed in collaboration with manufacturing engineers from the production planning department in order to place the spots within the reach of welding robots. Coordinates of each welding spot are recorded in a spreadsheet that is parametrically linked to the CAD data files of the sheet metal design of the car body. All files are available through the company's product data management (PDM) system. However, when assembling input files for numerical simulation, this information is not used by the engineers compiling these files. Assumptions of the connectivity between different components might differ from the original design. After simulation, the welding spots are no longer contained in the CAD model of the individual part reducing its value in the context of the actual body design. Lack of coordination, obvious in this example, reflects the different understandings and goals of different groups as well as lack of adherence to process steps and use of different tools. A better understanding of each other's intentions, different forms of representation, and information needs could improve the process. 
The example shows that there is a multitude of influences on how engineers communicate to coordinate their efforts. Communication is often perceived directly as a problem but can be difficult to recognize because of interactions with other factors, such as planning or product complexity. Managers of design processes need to have a sense of where processes can be influenced. This requires understanding of how factors are connected, so that effort is not misdirected by attending to the symptoms, yet possibly ignoring underlying causes. In practice, it is often possible to analyze a specific situation, however little theoretical understanding of the correlation of factors influencing communication has been published.

This study presents a network of factors affecting communication. It is structured as follows: After a description of the background and purpose of this research, the procedure of data acquisition and analysis is presented, encompassing four stages:

Acquisition of empirical data: Empirical data on factors influencing communication was acquired by applying the 'Communication Grid Method' (see Section 3 in this study, [9-11]) in industrial case studies. It provided numerical scores of the engineers' perceived current and desired states of factors influencing communication. Only data elicited on the current state provides input for all subsequent analyses.

Exploration of inter-variable correlations: In order to elicit correlations between values for factors (termed variables for statistical analysis purposes) statistical correlation analyses were performed, using Kendall's $t a u-b$ measure of association.

Exploration of network of linkages: The outcome of inter-variable correlation was further processed in order to find structural characteristics, such as cycles and clusters, using a software tool based on graph-theory [12].

Literature exploration of direction of correlations: Findings from previous stages were brought in conjunction with literature from various relevant disciplines in order to look for possible directions of influence.

Further, conclusions and implications for engineering research and practice are drawn and the results are critically reflected. The study closes with suggestions for further research.

\section{Background: Current Research}

As highlighted by many researchers and practitioners (e.g., [13-20]) communication is one of the critical success factors of collaborative design. This is especially relevant in complex product development due to the large number of both components and design participants involved in the process.
Allen $[21,22]$ has done pioneering work on the role of effective communication in product development processes since the early $1970 \mathrm{~s}$. He suggests that the degree of interdependence between engineers' work is directly related to the probability that they engage in frequent technical communication. Smith and Eppinger [23] and Sosa et al. [18] use task interdependency to identify the activities that require higher effort to coordinate. Loch and Terwiesch [24] present an analytical model to study the coupling of uncertainty, dependence, and communication, suggesting that average communication frequency increases with the level of uncertainty and dependence. In these studies, communication is mostly defined as information transmission. Consequently, the frequency and flow of information is measured.

As the example in the introduction shows, there is more to communication than information flow. Eckert and Stacey [25] concluded in their research that there are several interaction scenarios, such as 'handover' or 'joint-designing' where communication misalignments tend to occur due to, for example, a lack of overview of the sequence of tasks by the individual design engineers, lack of information flow, or misinterpretation of information [26].

The importance of communication in collaborative design is indisputable, yet it raises questions of how to research communication in collaborative design in order to improve the design process. Hales $[27,28]$ looks at several levels of influence from the macroeconomic, microeconomic, corporate, management, project team, and personal level and draws a comprehensive list of factors influencing the design process. Badke-Schaub and Frankenberger [29,30] examine a comprehensive list of 'prerequisites' influencing the design process in order to arrive at the characterization of critical situations. 'Prerequisites' range from individual, team, organizational, design task, and outcome to boundary conditions. In their analyses, communication is a key factor, but no description is given of what communication incorporates. Indications point to different group characteristics, such as group climate or quality of leadership as influencing communication in collaborative design. In researching whether the level of technological complexity affects project group communication, Roberts et al. [31] come to the conclusion that in moderately complex projects information sharing is greater than in highly complex projects despite the fact that there is a higher need of information. Chiu [32] concludes that the type and structure of team organization impacts communication. Tiernan et al. [33] detected that changes in organizational structure affect collaborative design. While the importance of communication is generally acknowledged, there is little consensus on how it can be directed or, at best, systematically improved. 
For the purpose of this study, communication is defined as the cognitive and social process by which messages are transmitted and meaning is generated. It can thus be seen as the vehicle by which behavior is coordinated [9,33-37]. Communication is influenced by a number of factors, which are assumed to be associated. How these factors are interrelated, directly and indirectly, remains has to be seen. The relational interdependence between the elements of a system determines a change of some parts, which are originally not affected [38].

It is postulated that understanding and managing of communication might be aided by gaining insight into its structure. This might come about through reflection in the form of assessment. Busseri and Palmer [39] concluded that self-assessment during the design process has a positive effect on how well a team functions, as it increases reflection. The beneficial effect of selfreflection in teams has been emphasized by several authors [40-43]. Badke-Schaub et al. [44] advocate education and training of engineers to increase reflection. Maier et al. $[9,10]$ developed a practical method of self-assessment - the 'Communication Grid Method' - to reflect on communication in engineering design. The method uses the designers' perceptions on the current and desired states of multiple factors influencing communication during a certain project phase as the assessment index (see next section) which is the basis for empirical data in this research project.

Insights into associations between factors impacting on communication is seen as a lever to increase understanding and make the complexity of communication more transparent.

\section{Acquisition of Empirical Data}

Data acquisition proceeded by using the 'Communication Grid Method' [9-11] which has been developed with the focus of assessing communication in collaborative design. The method aims at reflection in both senses of the word: to mirror back perceptions about communication in industrial practice as well as to trigger thinking about communication practices in a systematic way. It is based on the idea of process assessment via maturity grids in quality management [45] and software development [46]. Both have so far been adapted for instance to areas including technical innovation [47], project management [48], and design [49], but not yet to the assessment of communication in collaborative design. Therefore, Maier et al. $[9,75]$ focused on a maturity grid-based approach applied in a participatory group workshops. For the purpose of this study, the method functions solely as acquisition method for empirical data. In order to place the results in context, in what follows, the set up of the method is described.
Generally, in a maturity grid, levels of maturity are allocated against certain key aspects. Text descriptions inside the cells of the grid express different levels of maturity which show the development from an initial to a more advanced state for the considered subject [50]. In the 'Communication Grid Method' (CGM), $\approx 50$ factors influencing communication - elicited through a combination of ethnographic case studies in industry and analysis of relevant literature prior to this research project - are selected to which four levels of maturity are allocated [10]. The maturity levels are based on the idea of learning types from Argyris and Schön [51]. The CGM is administered in an interview or a structured group workshop to elicit the design engineers, perception on the current (as-is) and desired states (to-be) of factors influencing communication at a certain team interface. Paper-based grid sheets are distributed and scores by the design engineers on the current and desired states are collected (see Figure 1 as an excerpt of the full set of grid sheets. The set of grid sheets with definitions of factors and questions is listed in table format in Appendix Table A1).

When applying the CGM different influences (represented by a set of $\approx 50$ factors) are allocated to five levels of influence (product, information, individual team member, project team, and organization) which are subdivided into 11 areas of influence on communication in product development. Each area acts as a category, under which individual factors are subsumed. Two examples for subdividing areas into more detailed factors are shown in Table 1.

The CGM sheds light on both the current and the desired states of factors influencing communication as assessed by participants in the case studies. Thus, by correlating the values it is the assumption that an informative picture about the interdependencies among the selected factors can be drawn, based on the existing communication situation. Values for the desired states are not considered in this research.

In total, 38 engineers and managers completed the grid sheets in either individual interviews or group workshops. All case studies were concerned with communication at a certain team-interface with regard to a specific project at a specific design phase. All projects contained routine as well as non-routine design elements in order to design the product, whereas routineness is expressed on an axis, with the possibility of different degrees of routineness [52]. The definition of factors was given to all participants in the studies in order to provide a common reference point.

For the purpose of analyzing communication in product development, data from the following five companies was included:

- A large, globally operating company in information technology, developing and servicing software and 


\begin{tabular}{|c|c|c|c|c|c|c|}
\hline \multicolumn{7}{|c|}{ Teamwork } \\
\hline \multicolumn{7}{|c|}{ Please answer for your project team } \\
\hline \multicolumn{7}{|c|}{ Levels of maturity } \\
\hline Factors & A & B & 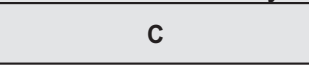 & D & $\begin{array}{c}\text { Current } \\
\text { score }\end{array}$ & $\begin{array}{c}\text { Desired } \\
\text { score }\end{array}$ \\
\hline Collaboration & $\begin{array}{l}\text { Everyone looks } \\
\text { solely after his } \\
\text { or her tasks }\end{array}$ & $\begin{array}{l}\text { Collaboration happens } \\
\text { only if asked for in } \\
\text { order to fulfil tasks }\end{array}$ & $\begin{array}{l}\text { Collaboration happens } \\
\text { proactively in order to learn } \\
\text { from others and improve } \\
\text { own approaches }\end{array}$ & $\begin{array}{l}\text { Collaboration is constructive, happens } \\
\text { regularly whenever necessary and } \\
\text { there is continuous effort to improve it }\end{array}$ & & \\
\hline $\begin{array}{c}\text { Common goals and } \\
\text { objectives }\end{array}$ & $\begin{array}{l}\text { Not known. No } \\
\text { thinking about it }\end{array}$ & $\begin{array}{l}\text { Known but everyone } \\
\text { follows just his or her } \\
\text { own goals }\end{array}$ & $\begin{array}{l}\text { Known and sometimes } \\
\text { consideration about the way } \\
\text { common goals can be } \\
\text { reached through working } \\
\text { together }\end{array}$ & $\begin{array}{c}\text { Entirely clear and identification with it } \\
\text { which is expressed in communication } \\
\text { and continuous effort to assess and } \\
\text { adjust goals and objectives and the } \\
\text { way to each them }\end{array}$ & {[} & \\
\hline Team identity & $\begin{array}{l}\text { There is none } \\
\text { and it is not seen } \\
\text { as necessary }\end{array}$ & $\begin{array}{l}\text { Small groups form } \\
\text { depending on the task } \\
\text { and these groups get } \\
\text { their identity through } \\
\text { the tasks }\end{array}$ & $\begin{array}{l}\text { Attitudes with respect to } \\
\text { team identity are } \\
\text { continuously reflected upon } \\
\text { in order to find a common } \\
\text { denominator }\end{array}$ & $\begin{array}{l}\text { There is a strong sense of belonging to } \\
\text { the team and continuous reflection on } \\
\text { how team identity can be kept up and } \\
\text { strengthened for the project }\end{array}$ & [ ] & ] \\
\hline & & & & & & \\
\hline
\end{tabular}

Figure 1. Example grid sheet 'teamwork'.

Table 1. Categorization of Factors in the 'Communication Grid Method'.

\begin{tabular}{|c|c|c|}
\hline Level of influence & Areas of influence & Examples of individual factors \\
\hline $\begin{array}{r}\text { Organization } \\
\text { Project } \\
\text { Individual } \\
\text { Information }\end{array}$ & $\begin{array}{l}\text { Organisational structure } \\
\text { Organisational culture } \\
\text { Teamwork } \\
\text { Reflection within project team } \\
\text { Personal development } \\
\text { Awareness } \\
\text { Information transmission/handling } \\
\text { Availability of information... } \\
\text { Media of communication } \\
\text { Expression of the product } \\
\text { Requirements }\end{array}$ & $\begin{array}{l}\text { Mutual trust } \\
\text { Handling of technical conflicts } \\
\text { Application of corporate vision and values } \\
\text { Transparency of decision making }\end{array}$ \\
\hline
\end{tabular}

providing technical consultancy. Communication between service support and development of one particular code-base of a particular software project was to be analyzed. The work incorporated routine as well as innovative solutions to a problem customers found in the company's software. Participants of the communication audit knew each other well and most had been in the company for more than 10 years.

- A small company producing electron beam and furnace technology, based in the UK. The 'works order' process was to be improved through an analysis of how a 'works order' flows through the company from its initial order to an offer. The focus of the audit lay on communication among the management team (engineering, manufacturing/ spares, sales, service, and finance). All members had been in the company for more than 15 years.

- A large aerospace company, based in the UK, designing, manufacturing, and servicing aero engines. Two studies within two distinct branches (civil and defense) of the company were conducted. In one project, the communication audit conducted investigated the state of communication at the interface between design and a service team of one 
particular aero engine. The other project aimed to diagnose the state of communication at the interface of preliminary design for one of the civil engines and the business unit designing IP turbine blades. In both cases, the participants knew each other well and most of them had been in the company for many years.

- A large automotive manufacturer, based in Germany. The audit looked at communication at the interface between embodiment design (CAD) and simulation (CAE) during the early phases of designing the body of a car for one particular vehicle series. The study focused on the design of the so-called 'trimmed body' for the serial development of one of the company's vehicle series. The observed interface to simulation was that of engineers involved in developing the function 'noise vibration harshness' (NVH). The majority of participants had been in the company for over 15 years.

\section{Exploration of Inter-variable Correlations}

Statistical correlation analysis was used in order to explore connections between factors influencing communication.

\subsection{Set Up}

Answers given in the grid sheets on the current states of 27 factors common across all industrial studies formed the basis of exploring correlations between factors influencing communication in product development. The population of people asked about selected factors was at least $N=30$. For statistical calculation purposes, factors are referred to as variables. As the empirical data acquired has the standard of an 'ordinal scale', Kendall's tau- $b$ was used for calculating the correlation [50,51]. For visualization purposes, the correlation matrix across all the participants was processed manually (see Appendix Table A2).

Correlations were categorized according to Brown [52]: Moderate low correlations range from 0.4 to $\leq 0.5$, moderate high from 0.51 to $\leq 0.6$, and high correlations from 0.61 to $\leq 0.8$. Only correlations at a significance level of at least $p<0.05$ and correlations with an absolute coefficient value of equal to and more than 0.4 were chosen. All of the correlations for further analyses, meeting the selection criteria in this study, are characterized by a positive correlation coefficient. The correlation coefficients are symmetrical. Consequently, the correlation matrix does not show which variable drives a particular correlation.

\subsection{Selected Results}

Four 'high' and eleven 'moderate-high' correlations were found, as well as 18 correlations having a 'moderate low' coefficient. Constrained by the selection criteria mentioned above (Section 4.1), Figure 2 and Appendix Table A2 show the complete set of correlations found.

As examples of the findings, representative instances are listed below. Variables that correlate with at least four other variables and show at least one 'high' correlation coefficient are termed 'core variables'. The results thus highlight:

- 'collaboration',

- 'mutual trust',

- 'overview of sequence of tasks in the design process', and

- 'autonomy of task execution'.

'Collaboration' shows correlations with nine other variables. 'Mutual trust' displays correlations with six other variables, and 'overview of sequence of tasks in the design process' is related to four other variables (bold in Figure 2). The statistically inferred importance of these correlations for design management is supported by literature (see Section 6).

Factors selected in this research project are a basis to generate hypotheses for further research on whether those four factors can be depicted as the core influences on communication in product design.

Findings in this section shed light on singular linkages, function as input for exploration of linkages beyond correlations between two variables, and form the basis for the literature analysis and critical reflection.

\section{Exploration of Clusters and Cycles}

In addition to the exploration of correlations between two factors, graph-theoretical analyses were performed to detect linkages between several factors.

\subsection{Clusters of Factors}

The correlation matrix was manually manipulated in order to visualize clusters among the 27 selected factors. Clusters in this context consist of factors that are completely linked amongst each other. Clusters that stand out based on the correlation matrix are highlighted in the rearranged matrix (Figure 3). 


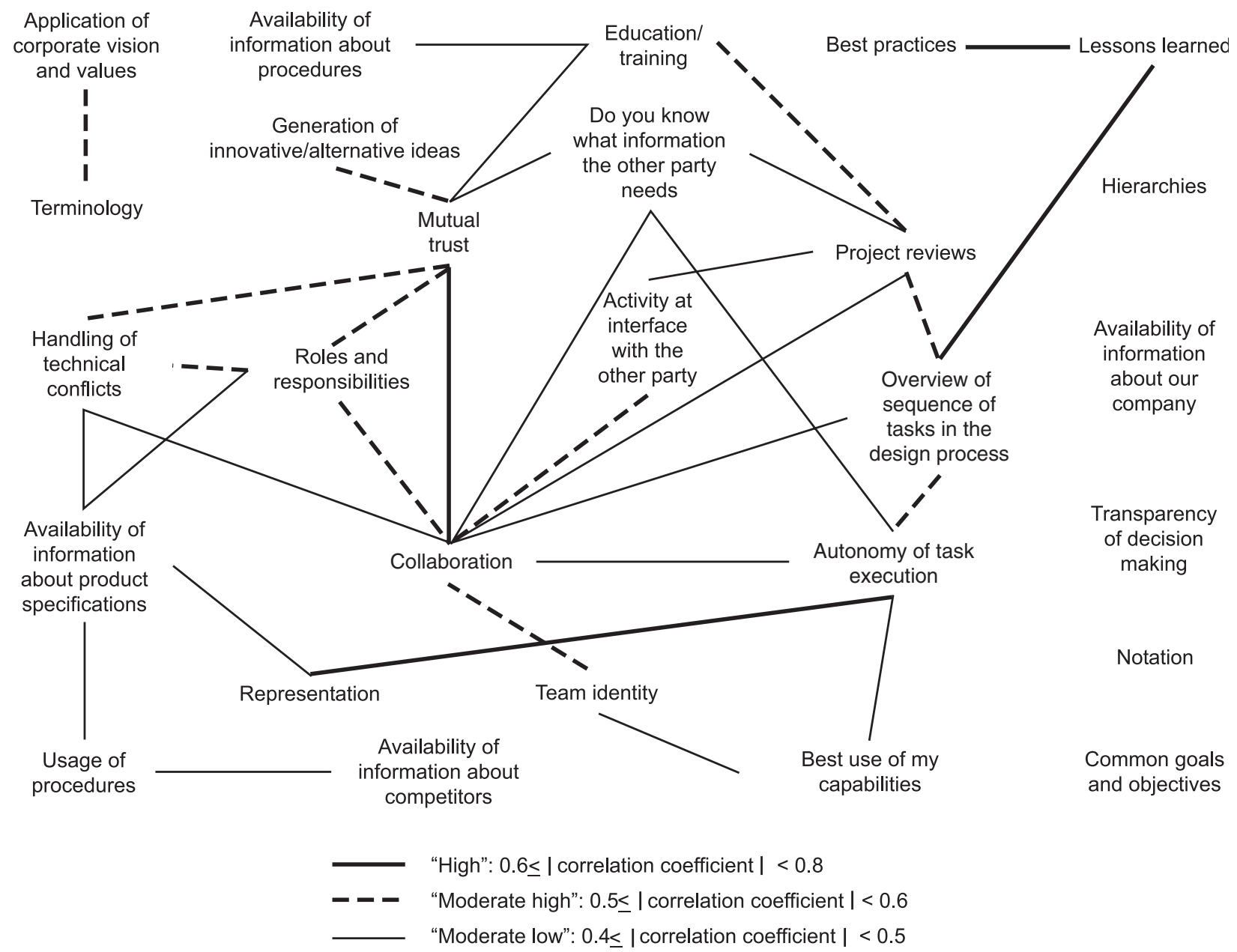

Figure 2. Network of all Correlation Coefficients.

In total, eight complete clusters were detected. As the clusters overlap, for visualization purposes, only Clusters A-D are highlighted in the matrix in Figure 3.

Clusters A-H encompass the following:

Cluster A: 'Availability of information about product specifications'; 'Handling of technical conflicts'; 'Roles and responsibilities'.

Cluster B: 'Handling of technical conflicts'; 'Roles and responsibilities'; 'Mutual trust'; 'Collaboration'.

Cluster C: 'Mutual trust'; 'Collaboration'; 'Do you know what information the other party needs'.

Cluster D: 'Collaboration; 'Do you know what information the other party needs'; 'Autonomy of task execution'.

Cluster E: 'Collaboration'; 'Autonomy of task execution'; 'Overview of sequence of tasks in the design process'.

Cluster F: 'Collaboration'; 'Overview of sequence of tasks in the design process'; 'Project reviews'.

Cluster G: 'Collaboration'; 'Project reviews'; 'Activity at interface with the other party'.
Cluster H: 'Collaboration'; 'Project reviews'; 'Do you know what information the other party needs'.

Clusters can be viewed as groupings that are compact in comparison to the rest of the network, i.e., they have a higher coherence than their environment. In product architectures, they are, for example, used to find purposeful boundaries for modularization of a product [56]. For the purpose of this research, factors contained in a cluster could be read as inseparable. To shed light on the particular communication phenomenon inherent to each cluster, a more coarse level denomination might be applicable for each cluster.

\subsection{Indirect Linkages Between Factors}

Cycles occurring in the network of linkages refer to loops of linked nodes. However, as the chains of cause and effect cannot be concluded from the correlation matrix, cycles cannot be termed feedback loops. As it is common in graph-theory, the term 'node' is used for a factor influencing communication in product development. The length of the cycle refers to the number 


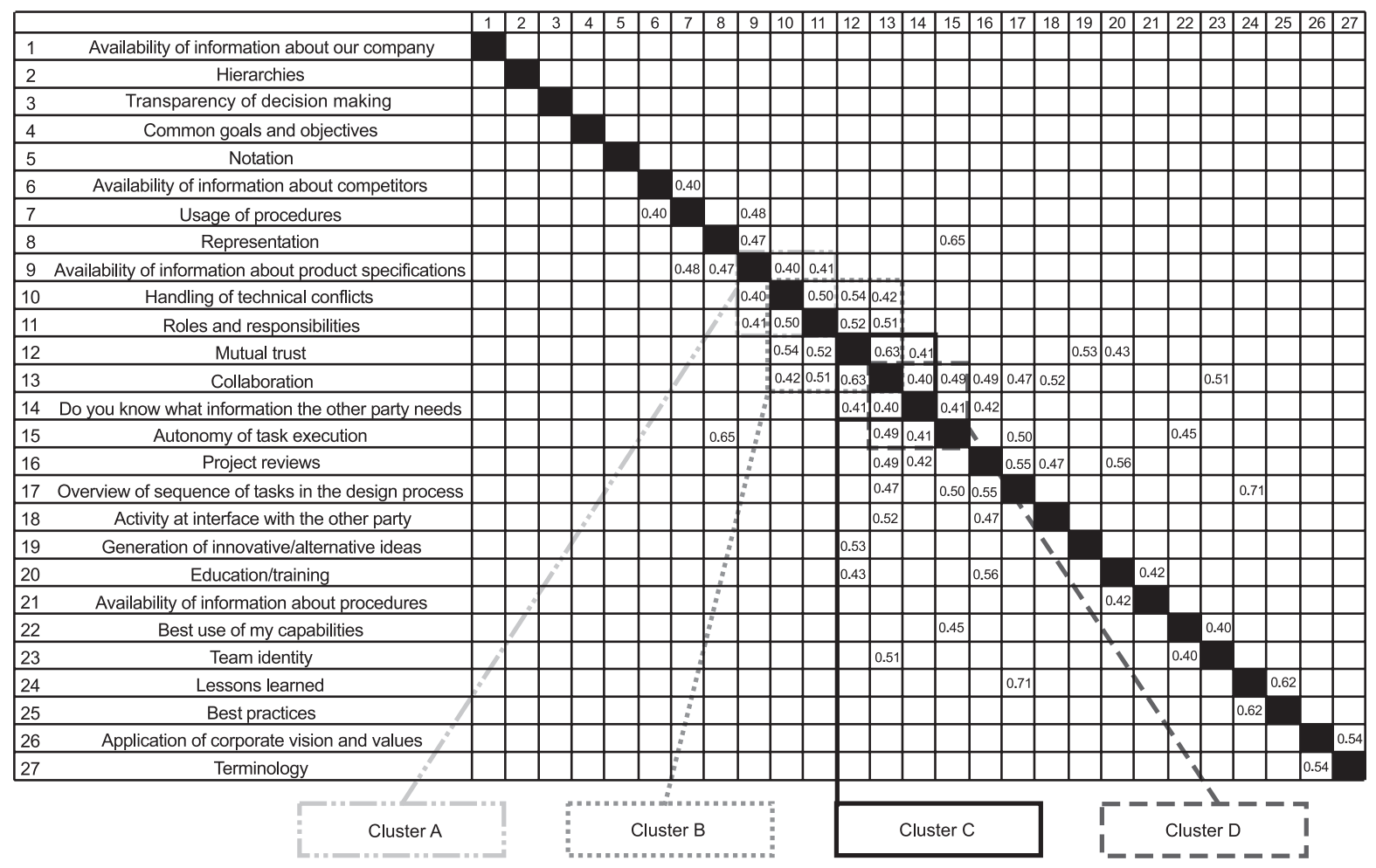

Figure 3. Clustures $A$ to $D$ in correlation matrix.

of nodes a cycle is consisting of. Accordingly, a linkage between two factors is also called 'edge'. Cycles depict network structures in which all nodes are circularly and indirectly linked to each other. The more often a node appears in the overall number of cycles, the more (indirectly) it is linked to other elements present in those cycles (Figure 4(b)). Equally, a high occurrence of a certain edge emphasizes its importance in respect to the number of existing cycles (Figure 4(c)).

As the chains of cause and effect are not defined for the linkages, the explanatory power of the cycle analysis is limited. For example, the build-up of resonances through feedback to the starting node cannot be observed in this kind of model. Yet, analyses point to the importance of looking at the web of linkages as a whole, especially to recognize the existence and importance of indirect linkages between factors (e.g., [57]). Furthermore, the more frequent a single node occurs in the overall network, the higher the importance and impact for the overall structure.

In total 467 cycles were found in the network of linkages. The occurrence of cycles per cycle length is illustrated in Figure 4(a). The minimum cycle length is 3 as a cycle must at least contain three different factors. Cycles with this length also stand for the smallest possible clusters as the three nodes in these cycles are fully linked with each other.
The 467 cycles show that changing the status of a factor is likely to cause many unintended changes on factors not directly linked with the initially changed factor. Certain cycles might possibly qualify as feedback loops; for instance, a good establishment of mutual trust typically enhances the understanding and implicit repartition of roles and responsibilities, thus enhancing collaboration. In turn, good collaboration positively influences trust among the people collaborating.

Only 14 of the 27 considered factors (nodes) are part of all 467 cycles as visualized in Figure 4(b). The factor 'collaboration' appears most often in the detected cycles. In 445 of the 467 cycles, this factor contributes to the existence of the respective cycle. Thus, 'collaboration' must be seen as a factor of major importance in the network of factors influencing communication in product development. However, as communication as such is about collaborating, it is also evident that the subjective perception of the quality of collaboration is a key factor towards evaluating communication. Another important factor in this context is 'mutual trust' as being part of 395 of the 467 cycles.

As indicated earlier, the two factors 'collaboration' and 'mutual trust' play a major role in almost all cycles. Only two (Examples 1 and 2) can be set up without either one. As the linkage between the factors 'autonomy of task execution' and 'representation' 


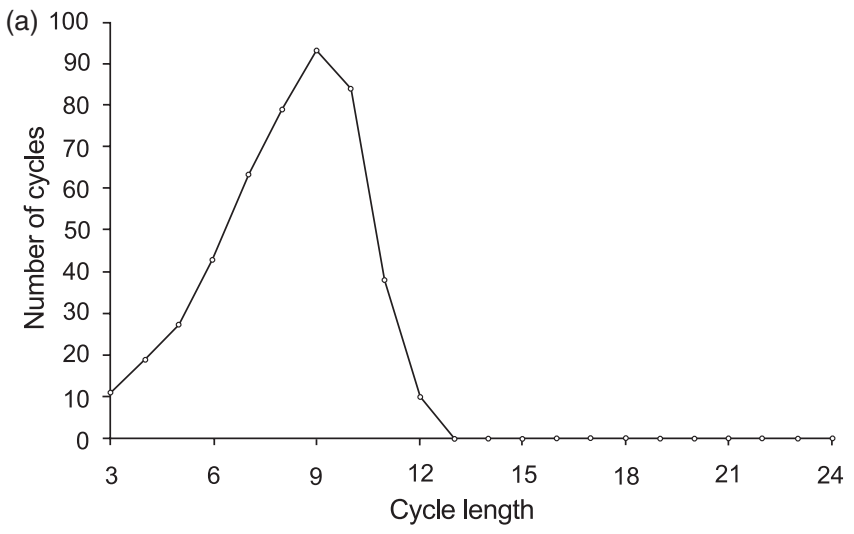

(c)

\begin{tabular}{|c|c|}
\hline F 01 & Collaboration \\
\hline $\mathrm{F} 02$ & Mutual trust \\
\hline $\mathrm{F} 03$ & Autonomy of task execution \\
\hline F 04 & Project reviews \\
\hline F 05 & Handling of technical conflicts \\
\hline F 06 & Roles and responsibilities \\
\hline F 07 & $\begin{array}{l}\text { Do you know what information } \\
\text { the other party needs }\end{array}$ \\
\hline F 08 & $\begin{array}{l}\text { Availability of information } \\
\text { about product specifications }\end{array}$ \\
\hline F 09 & Representation \\
\hline F 10 & $\begin{array}{l}\text { Overview of sequence of tasks } \\
\text { in the design process }\end{array}$ \\
\hline F 11 & Education/training \\
\hline F 12 & $\begin{array}{l}\text { Activity at interface } \\
\text { with the other party }\end{array}$ \\
\hline F 13 & Best use of my capabilities \\
\hline $\mathrm{F} 14$ & Team identity \\
\hline
\end{tabular}
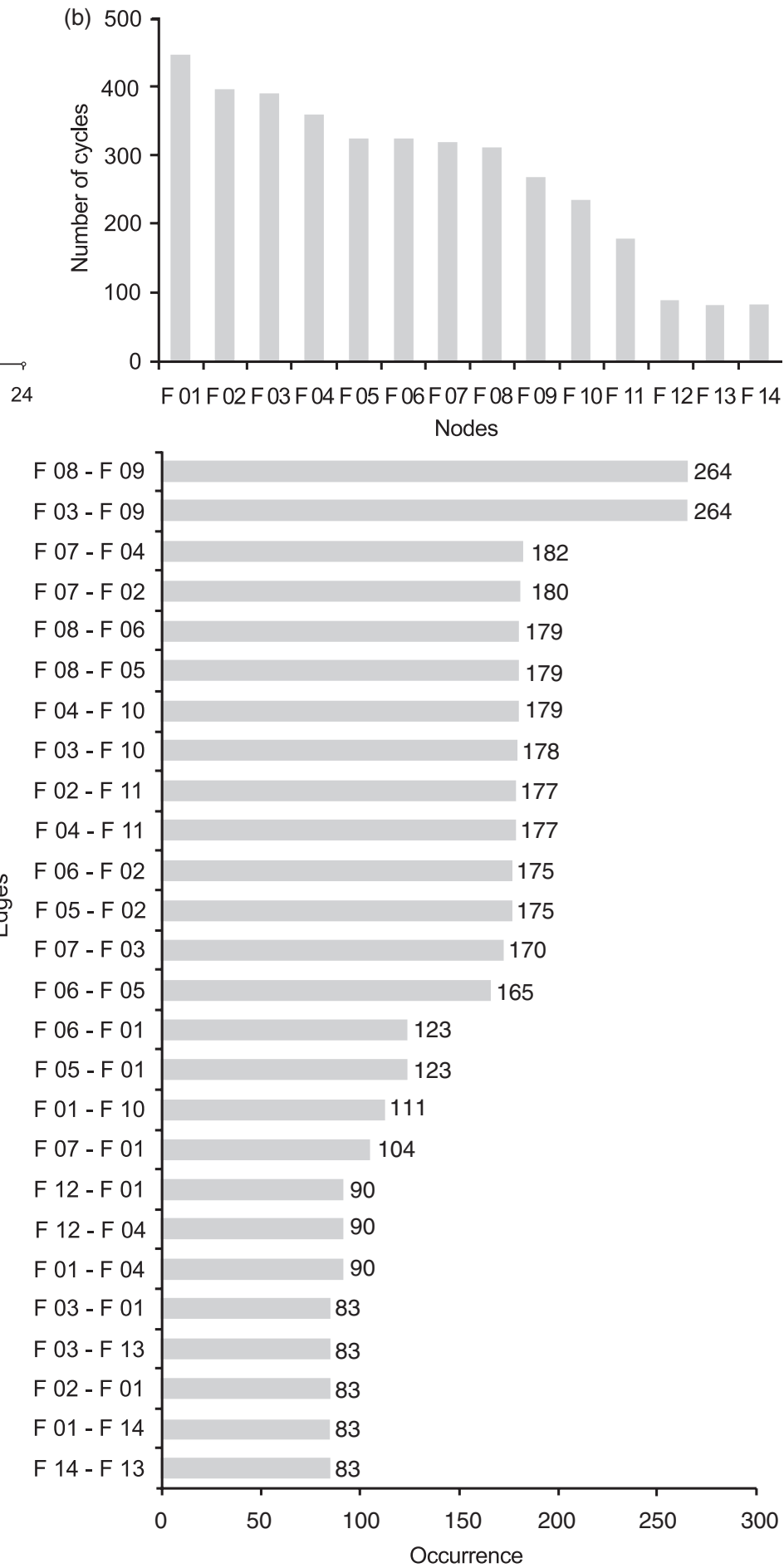

Figure 4. Top left (a) Number of cycle per cycle length; Top right (b) Occurrence of nodes in all detected cycles and (c) Occurrence of edges in all detected cycles.

and between 'autonomy of task execution' and 'availability of information about product specifications' occurred both in 264 of the 467 cycles (see Figure 4(b)), Example 3 is of interest. All three examples contain the four most frequently occurring nodes (see Figure 4(c)).
- Example 1 (cycle length=4): 'Project reviews' - 'Do you know what information the other party needs' 'Autonomy of task execution' - 'Overview of sequence of tasks in the design process' - 'Project reviews'.

- Example 2 (cycle length=3): 'Handling of technical conflicts' - 'Availability of information about 


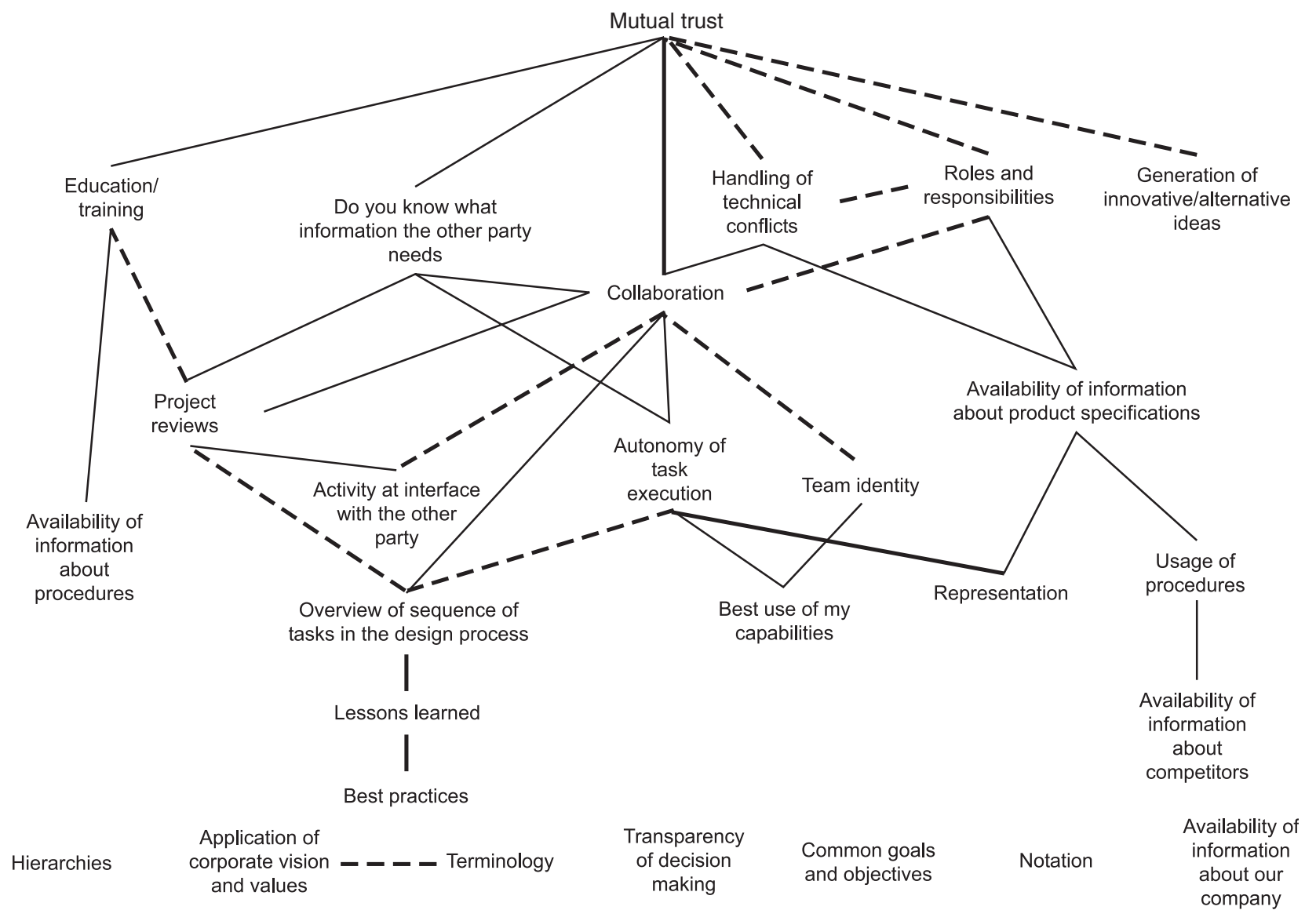

Figure 5. Impact of 'trust' on other factors (ordered as hierarchy across several layers).

product specifications' - 'Roles and responsibilities' 'Handling of technical conflicts'.

- Example 3 (cycle length = 5): 'Collaboration' - 'Roles and responsibilities' - 'Availability of information about product specifications' - 'Representation' 'Autonomy of task execution'- 'Collaboration'.

Analyzing cycles leads to detection of indirect linkages. These linkages can be brought into the form of a hierarchy. 'Mutual trust' and 'collaboration' act as central starting points for hierarchies. The example in Figure 5 shows nodes that are related and ordered in a way that their relation to 'mutual trust' is depicted in a hierarchical structure. Several layers of impact are shown. The further away from the starting point, the lower the impact.

Following indirect linkages, some factors, not explicitly connected in the graph shown, are strongly linked indirectly [58], e.g., via a third one (Figure 5): 'Do you know what information the other party needs' and 'overview of sequence of tasks in the design process' is the most important indirect linkage, as these two are connected via a number of other pathways.
At a lower level, the following factors form indirect linkages, such as:

- 'Activity at interface with the other party' and 'overview of sequence of tasks in the design process'.

- 'Do you know what information the other party needs' and 'education/training'.

- 'Availability of information about product specifications' and 'mutual trust'.

- 'Availability of information about product specifications' and 'collaboration'.

This, again, highlights the importance of understanding factors as an interconnected network.

\subsection{Preliminary Summary: Network of Factors as a Whole}

Exploring the network of factors based on the correlation analysis resulted in eight complete clusters after rearranging the correlation matrix. The analysis of nodes and edges resulted in linkages which were not detected by the correlation analysis, given the selection 
criteria used. They were manually added to the rearranged correlation matrix in order to view larger completed clusters, in which only one or two linkages were missing. By this procedure, nine factors with a high degree of linkage among each other were elicited:

- 'availability of information about product specifications',

- 'handling of technical conflicts',

- 'roles and responsibilities'

- 'mutual trust',

- 'collaboration',

- 'do you know what information the other party needs',

- 'autonomy of task execution',

- 'project reviews', and

- 'overview of sequence of tasks in the design process'.

Cycles, cycle lengths, occurrences of nodes and edges in the network of factors were analyzed. In the 467 detected cycles the nodes 'collaboration' and 'mutual trust' play an important role for the existence of cycles. Changing the status of a factor might have influence on many other factors, if the changed factor belongs to the group of factors showing a high linking degree among each other. Further, changing a certain factor which occurs in many cycles might have unintended effects on not directly linked factors that are part of the respective cycles.

\section{Literature Analysis: The Search for Direction}

As elicited correlations and cycles are undirected, further evidence is needed in order to determine a possible causal direction. To this end, literature from a number of disciplines, such as new product development, management science, and psychology was consulted.

\subsection{Correlations Supported by Literature}

Table 2 summarizes evidence from the literature drawn to support correlations explored in this study.

Determination of possible directions of cause and effect is not conclusive. Yet, evidence for each possible direction has been found. With regard to the first example of correlating factors 'collaboration' and 'team identity', references in the literature seem to suggest that 'team identity' is one of the drivers of 'collaboration' $[29,59,60]$. Concluding from the reviewed literature a direction seems to be apparent. The factor 'roles and responsibilities' seem to be another driving factor of 'collaboration' [61-63]. In terms of 'mutual trust' and 'collaboration', evidence in the literature can be found which supports both directions [64-67]. Interviewing engineers from 34 medium-sized manufacturing companies with regard to their business relation with the customer and supplier, Bstieler [67] concludes that a higher level of trust is positively related to perceived continuity of collaborative development projects. This supports a bidirectional influence. With regard to 'autonomy of task execution' and 'representation', Eckert et al. [68] suggest that if you do not have clear representations you need to negotiate and cannot carry your tasks out autonomously.

Although evidences have been found which indicate trends, results have to be read with a note

Table 2. Evidence from literature

\begin{tabular}{|c|c|c|c|}
\hline Factor 1 & & Factor 2 & Reference \\
\hline \multirow{4}{*}{ Collaboration } & $\longleftarrow$ & \multirow{4}{*}{ Team identity } & Collarelli and Boos [55] \\
\hline & $\leftarrow$ & & Vianen and Dreu [60] \\
\hline & $\leftarrow$ & & Badke-Schaub and Frankenberger [29] \\
\hline & $\rightarrow$ & & Kuhn and Nelson [69] \\
\hline \multirow{3}{*}{ Collaboration } & $\longleftarrow$ & \multirow{3}{*}{$\begin{array}{l}\text { Roles and } \\
\text { responsibilities }\end{array}$} & Ahuja et al. [63] \\
\hline & $\longleftarrow$ & & Perry and Sanderson [61] \\
\hline & $\leftarrow$ & & Moenaert et al. [62] \\
\hline \multirow{4}{*}{ Collaboration } & $\leftarrow$ & \multirow{4}{*}{ Mutual trust } & Krackhardt and Stern [64] \\
\hline & $\leftrightarrow$ & & Bstieler [67] \\
\hline & $\leftarrow$ & & $\mathrm{Ng}$ and Chua [66] \\
\hline & $\rightarrow$ & & Wong and Cheung [65] \\
\hline \multirow{2}{*}{ Handling of technical conflicts } & $\leftarrow$ & \multirow{2}{*}{ Mutual trust } & Susman et al. [70] \\
\hline & $\longleftarrow$ & & Newman [71] \\
\hline Generation of innovative/alternative ideas & $\longleftarrow$ & Mutual trust & Thamhain [72] \\
\hline \multirow{2}{*}{$\begin{array}{l}\text { Overview of sequence of tasks } \\
\text { in the design process }\end{array}$} & $\leftarrow$ & \multirow{2}{*}{$\begin{array}{l}\text { Lessons } \\
\text { learned }\end{array}$} & Ayas [73] \\
\hline & $\leftarrow$ & & Klein et al. [3] \\
\hline $\begin{array}{l}\text { Overview of sequence of tasks } \\
\text { in the design process }\end{array}$ & $\longleftarrow$ & Project reviews & Perry and Sanderson [61] \\
\hline Autonomy of task execution & $\leftrightarrow$ & Representation & Eckert et al. [68] \\
\hline
\end{tabular}


of caution. Studies have used different research methods and people participating in the studies dealt with different tasks. Consequently, results presented in this research provide directions as to where suggestions seem apparent.

\subsection{Correlations not Detected in Reviewed Literature}

Some statistically suggested correlations could not be found in the literature:

- 'Roles and responsibilities' $\leftrightarrow$ 'Mutual trust';

- 'Roles and responsibilities' $\leftrightarrow$ 'Handling of technical conflicts';

- 'Overview of sequence of tasks in the design process' $\leftrightarrow$ 'Autonomy of task execution';

- 'Education/training' $\leftrightarrow$ 'Project reviews';

- 'Terminology' $\leftrightarrow$ 'Application of corporate vision and values'.

Several reasons might contribute to the fact that no evidence in the literature was found. Some literature might have escaped the authors' radar, some might have not been appropriate, definitions used in the original data acquisition phase for the individual factors (see Appendix Table A2) might not have concurred with the definitions used in other research projects, or, factors might simply not be linked directly. Despite the significance level chosen, correlations might just be statistical correlations.

\subsection{Potential Indirect Linkages}

Another aspect why no reference was found for a detected correlation might be that the two respective factors are only linked indirectly. This could apply, for example, to the correlation between the factors 'roles and responsibilities' and 'mutual trust' (see Figure 6).

Correlation between 'collaboration' and 'roles and responsibilities' is supported by three references in the reviewed literature and correlation between the factors 'collaboration' and 'mutual trust' is supported by four references (see Table 2). However, no references for the correlation between the factors 'roles and responsibilities' and 'mutual trust' were found. Within this context, it leads to the assumption that they could be indirectly linked, bearing the data acquisition process in mind.

\section{Conclusions}

The overall objective of this study was to explore interrelations between factors influencing communication in product development emerging from data acquired through empirical studies. A communication grid analysis in five case studies in industry yielded empirical data from engineers and managers scoring their perception on the current state of factors influencing communication.

As correlations statistically inferred are nondirectional, possible directions were elicited through intensive and extensive literature reviews. In addition to illustrating inter-variable correlations, cycles using graph-theory are presented.

Results presented in this study are seen as initial attempts to exhibit interconnections between factors pertinent to design and communication. As in any other empirical study that collected data from empirical studies with small samples within each study, the generality of the findings cannot be claimed before completing similar studies. However, the authors would expect to obtain analogous results in other projects

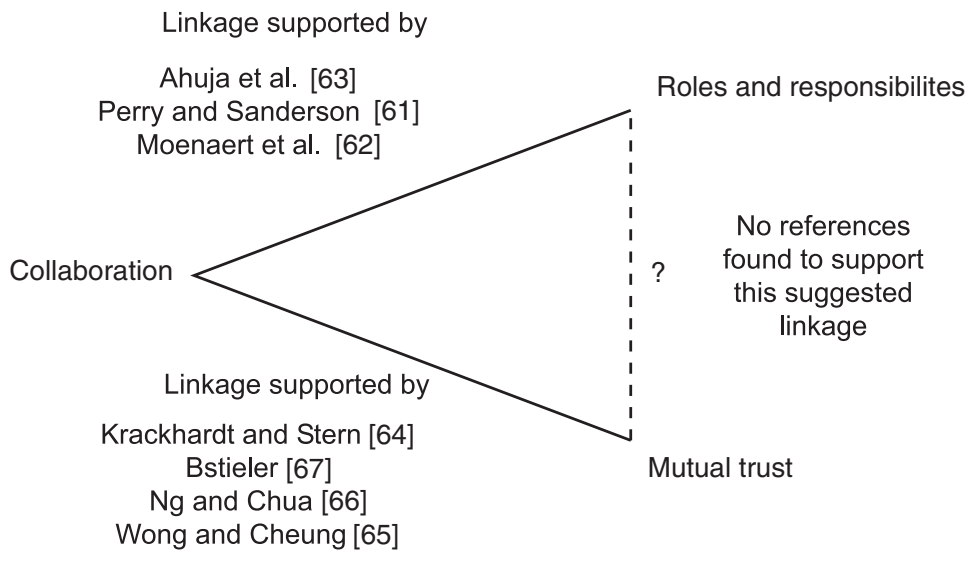

Figure 6. 'Roles and responsibilities' and 'trust' indirectly linked by 'collaboration'. 
developing complex systems. This study is explorative in nature and as such, drawing explicit normative conclusions is avoided.

The findings in this study enrich the understanding of communication as a major determinant in collaborative design by showing different factors and their interrelations impacting on communication and on the design process. This analysis has yielded a number of interesting results:

(1) Core factors: The factors 'mutual trust', 'collaboration', 'roles and responsibilities', 'project reviews', 'availability of information about product specifications', 'handling of technical conflicts', 'do you know what information the other party needs', 'autonomy of task execution', and 'overview of sequence of tasks in the design process', possessing of a high linking degree, are portrayed as core factors that influence communication in product development.

As can be seen in Figure 2, the analysis shows the factors 'hierarchies', 'availability of information about the company', 'transparency of decision making', and 'common goals and objectives' are below the selected criteria of at least 'moderate-high' correlation coefficient and statistically significant values. They might act as 'other variables' which also cause communication in design, as any covariance they share with the selected independent variable might falsely have been attributed to that independent variable.

(2) Clusters of factors, such as Cluster A ('availability of information about product specifications', 'handling of technical conflicts', and 'roles and responsibilities') as shown in Section 5.1 represent groups inside which every node correlates with every other node. For example, Cluster $A$ could be named 'finding compromises', given that technical conflicts can only be purposefully resolved if data on product specifications are available and if roles and responsibilities in particular for the process of decision making is clear.

(3) Cycles: Analyzing cycles led to the detection of indirect linkages. These linkages can be brought into a hierarchy. 'Mutual trust' and 'collaboration' act as central starting points for hierarchies. Changing the state of a factor is likely to cause many unintended changes on factors not directly linked with the initially changed factor.

(4) Direction of which way causation flows through literature: Concluding from the reviewed literature, directions, such as the following are suggested: 'team identity' and 'roles and responsibilities' seem to be drivers of 'collaboration'. These analyses provide examples to be compared with results of other research projects.

\section{Implications}

\subsection{Implications of Findings for Research}

Contributions of this work to current research in concurrent product development are highlighted below:

(1) Theoretical exploration into connections of factors: It presents a theoretical exploration into connections of factors influencing communication in collaborative design based on empirical studies in different industry sectors. It might open a stream of research into eliciting further evidence with regard to possible and plausible chains of multiple cause and effects. Whereas the literature points toward importance of individual factors, correlations with other factors which point to trends or possibly regularities were so far rarely found. This research project contributes towards complementation.

(2) Generating hypotheses and questions: The findings in this study provide empirical support for a set of relationships between factors influencing communication in product development. The range of findings - in particular exposition of indirect linkages - support the general statement that there are a number of influences on communication in engineering design which need to be viewed in context with other influencing factors. The results lead towards generating the following exemplary hypotheses and questions, falsification of which is subject to further research.

(a) Correlations which have been found in this research but not yet supported by literature, such as the link between: 'overview of sequence of tasks in the design process' and 'autonomy of task execution'. It could be hypothesized that the greater the overview, the greater the ability to collaborate, thus a reduced need for clear task separation. Likewise, it could be possible that the greater the overview, the greater the ability of a team to draw clear distinctions between tasks and the greater the ability to assess expertise of colleagues and judge when to contact them and when best not to.

(b) 'Overview of sequence of tasks in the design process' is influenced by 'education/training' or vice versa as they are indirectly linked. Could a change in one have a knock-on effect on the other? Or would it depend on the nature of the linkage?

(3) Assessment of communication: Although communication is inherently subjective and boundaries of definition of factors are drawn differently; this research provides an attempt towards making communication more 'tangible' and accessible for research and management. It supports the quest for 
a taxonomy permitting an assessment of collaborative design communication.

\subsection{Implications of Findings for Designers and Managers}

This research emphasizes the importance of communication for concurrent engineering in terms of communication as coordinating behavior towards a common goal. Studies show that it is beneficial for the individual engineer and the design managers to be aware of how communication can be structured (e.g., using the factors as influences applied in this research) and how those factors are interconnected.

The example, described in the introduction about a lack of coordination of using available information on welding spots during the design of an automotive body. The clear establishment of common goals, for example, by working towards one common data model reachable through a common access portal to use available data best possible, could be a purposeful entry point. Knowing that, furthermore, a better coordination of preceding and following process steps is necessary, this could be consolidated introducing a project review of recent projects to establish 'lessons learned' for all engineers involved, thus improving their knowledge about each others information needs.

The results can be a basis to expose patterns of connections between factors. This knowledge could then be used in support for design management. It is believed that the presentation of interrelations encourages recognition of patterns. Recognition of patterns is thus facilitated through prior exposition via analysis. Following Meijer [74], in the world of management, the word complex is often a synonym for complicated or difficult, involving many factors and uncertainty. The results presented above could function as a starting point for preparation of managerial decision making which could thus also reduce uncertainty.

In other words, this research has important implications for managers from two different perspectives. From a strategic viewpoint, exposition of the network of factors influencing communication in product development based on empirical data might provide some insight into the types of factors to consider in designing an environment where design teams collaborate most effectively. From a tactical or operational viewpoint, findings in this study might provide decision-support and a starting point for intervention actions. Referring back to what has been said earlier with regard to seeing communication as a complex system, increasing transparency into the network of connected factors might reduce uncertainty.

\section{Critical Reflection of Results}

Some concerns to be addressed when exploring correlations between factors influencing communication statistically are the following:

(1) Number of participants: Limitations of this work concern the number of participants in these studies. Further studies should be made to validate the generality of the results. Extension of empirical data might show if the assumed linear behavior of the correlations can be confirmed, a topic discussed in Section 10 (Future Research). A larger number of responses would also allow for consideration of more than 27 factors in future research projects.

(2) Conceptual similarity: High correlations $(>0.60)$ and significant correlations ( $\min p \leq 0.05$ ) were the selection criteria and existed between the different factors. High correlation between factors may indicate an overlap in the actual factor being evaluated from a conceptual standpoint. While individual analyses may support specific correlations between selected factors, the factor itself may not be conceptually distinguishable.

An example could be the linkages between 'lessons learned' and 'overview of sequence of tasks in the design process' and between 'lessons learned' and 'best practices' which are characterized by a 'high' correlation coefficient. They are not part of any cycle. Yet, they appear as strong correlations. They can be viewed as small clusters being tightly related to one another. Often, as the studies have shown, users do not explicitly differentiate between the two latter ones, which basically document experience and knowledge in the process. Equally, although there are more 'ingredients' to lessons learned, knowledge about the sequence of process steps is for many engineers a major purpose of documenting lessons learned.

(3) Frequency of occurrence: The analysis was based on the detected frequency of occurrence and strength of correlation. Frequencies of occurrence have a powerful influence on later judgments of its value. The issue is to decide which correlations are causally meaningful [75]. However, the ability seems to be compromised when there is no clear way to decide how much and what type of causal understanding is needed. Evidence seems to be gathered and understood as converging to support a given correlation. In the present case, for example, through the various analyses (statistical, graphtheoretical, literature) 'collaboration' and 'mutual trust' seem to indicate thematic centrality. It might indicate a 'valid' tendency, it might, however, be 
a skeletal set of a causal pattern that most people seem to use in similar ways.

(4) Causal relations: The complexity and variety of causal patterns will make it clear that one cannot possibly track all causal patterns associated with factors influencing communication. One cannot exhaustively assess all causal patterns that people notice both because there are too many domains to examine and because there is no easy way to quantify the full range of what might be known and compare it to what is known. A literature review is used to detect potential causal relations.

(5) Lens: As much as detected correlations might be used as guidance or orientation points it must be noted that one might often use this kind of knowledge as a lens to interpret reality and, in looking through this lens, is often unaware of the ways in which it guides one to track some sort of causal relations more effectively than others [76].

\section{Future Research}

Part of the contribution of this study lies in providing a starting point for further research. For future work, we ask ourselves whether found interrelations can be used to generate hypotheses and questions (see Section 7, Conclusions) that can be tested in further empirical studies and ultimately form the basis for guidelines. In order to do that, preliminary questions need to be answered with regard to the nature of correlations found.

\subsection{Exploring the Nature of Correlations}

It is assumed that in this network of factors influencing communication there is no centralized controller which means that global behavior emerges probably as a result of concurrent local actions. Such networks are typically modeled as multiple nodes, each node representing a state variable with a given value. Network dynamics is determined by the nature of the influences between nodes [3]. Therefore we need to ask ourselves, whether the influences are linear or not and are they symmetric or not? Yet, this assumption needs to be investigated further. The algorithm used to compute correlations is based on linear influences thus understating possible nonlinear relationships. Linear networks are described as having a single attractor, i.e., a single configuration of node states that the network converges towards no matter what the starting point, corresponding to the global optimum. Symmetric networks are ones in which influences between nodes are mutual (i.e., if node A influences node B by amount X then the reverse is also true), while asymmetric networks (if they have cycles in them) add the complication of having dynamic attractors, which means that the network does not converge on a single configuration of node states but rather cycles indefinitely around a relatively small set of configurations [3].

\subsection{Exploring Causal Relations of Correlations Over Time}

Reviewing literature is one possibility to receive more information about the chains of cause and effect of the correlations suggested by the performed data analyses. Another approach could be to perform detailed case studies and asking the participants in concurrent design projects directly which factor influences the other factor of a certain linkage.

It would also be interesting to see whether exposed correlations can be traced over time. Data gathered for this research project was acquired at a certain point in time. Case studies performed at a certain time could be repeated during different stages of the design process.

\subsection{Incorporation of 'Moderate-low', 'Weak', and 'Negative' Correlations}

In this study, only linkages suggested by a 'moderate high' or 'high' correlation coefficient were compared with findings in the literature. In future research projects, 'moderate low' and 'weak' correlations could also be part of the literature review. In addition, statistical analyses in this study are based on positive correlations. Negative correlations were also found, yet not among the decision criteria applied in this study.

\section{Acknowledgments}

The authors appreciate the assistance of the engineers and managers at all five industrial collaborators. Further, the authors are grateful to the editors and two anonymous reviewers for their helpful comments.

\section{Appendices}

The appendix consists of a table with a glossary of how the factors used in this study have been defined including the full set of grid sheets (Appendix Table A1) and the complete correlation matrix (Appendix Table A2). 


\section{References}

1. Wheelwright, S.C. and Clark, K.B. (1992). Revolutionizing Product Development, Quantum Leaps in Speed, Efficiency, and Quality. New York: The Free Press.

2. Friedman, T.L. (2005). The World Is Flat: A brief History of the Twenty-first Century. New York: Farrar, Strauss and Giroux.

3. Klein, M., Sayama, H., Faratin, P. and Bar-Yam, Y. (2003). The Dynamics of Collaborative Design: Insights from Complex Systems and Negotiation Research, Concurrent Engineering, 11(3): 201-209.

4. Bucciarelli, L.L. (1988). An Ethnographic Perspective on Engineering Design, Design Studies, 9(3): 159-168.

5. Détienne, F., Martin, G. and Lavigne, E. (2005). Viewpoints in Co-design: A Field Study in Concurrent Engineering, Design Studies, 26(3): 215-241.

6. Sapuan, S.M., Osman, M.R. and Nukman, Y. (2006). State of the Art of the Concurrent Engineering Technique in the Automotive Industry, Journal of Engineering Design, 17(2): 143-157.

7. Andersson, K. (1999). A Design Process Model for Multiview Behaviour Simulations of Complex Products, In: Proceedings of DETC '99, 1999 ASME Design Engineering Technical Conferences, 12-15 September.

8. Großmann, T. (1998). Future Orientation of CAE Applications in the Passenger Car Development, VDI-Berichte 1411, Düsseldorf.

9. Maier, A.M., Eckert, C.M. and Clarkson, P.J. (2006). Identifying Requirements for Communication Support: A Maturity Grid-inspired Approach, Expert Systems with Applications, 31(4): 663-672.

10. Maier, A.M., Kreimeyer, M., Herfeld, U., Deubzer, F., Lindemann, U. and Clarkson, P.J. (2006). Reflecting Communication: A Key Factor for Successful Collaboration between Embodiment Design and Simulation, In: Proceedings of International Design Conference - Design 2006, Dubrovnik, pp. 1483-1490.

11. Maier, A.M. (2007). A Grid-based Assessment Method of Communication in Engineering Design, Ph.D Dissertation, Cambridge: Engineering Department, University of Cambridge.

12. Maurer, M., Boesch, N.-O., Tzonev, B. and Sheng, G. (2005). A Tool for Modelling Flexible Product Structures MOFLEPS, In: Engineering Design and the Global Economy, 15th International Conference on Engineering Design (ICED'05), Institution of Engineers Australia, Melbourne.

13. Hales, C. (2000). Ten Critical Factors in the Design Process, In: Proceedings of ASM/ASME Conference on Failure Prevention Through Education - Getting to the Root Cause, Strongsville, Materials Parks (OH), pp. 49-55.

14. Morelli, M.D., Eppinger, S.D. and Gulati, R.K. (1995). Predicting Technical Communication in Product Development Organizations, IEEE Transactions on Engineering Management, 42(3): 215-222.

15. Van den Bulte, C. and Moenaert, R.K. (1998). The Effects of R\&D Team Co-location on Communication Patterns Among R\&D, Marketing, and Manufacturing, Management Science, 44(11): 1-18.

16. Gupta, A.K., Raj, S.P. and Wilemon, W. (1986). A Model for Studying the R\&D/Marketing Interface in the Product Innovation Process, Journal of Marketing, 50: 7-17.
17. Sosa, M.E., Eppinger, S.D. and Rowles, C.M. (2004). The Misalignment of Product Architecture and Organizational Structure in Complex Product Development, Management Science, 50(12): 1674-1689.

18. Sosa, M.E., Eppinger, S.D., Pich, M., Mc Kendrick, D.G. and Stout, S.K. (2002). Factors that Influence Technical Communication in Distributed Product Development: An Empirical Study in the Telecommunications Industry, IEEE Transactions on Engineering Management, 49(1): 45-58.

19. Yap, C.M. and Souder, W.E. (1994). Factors Influencing New Product Success and Failure in Small Entrepreneurial High-technology Electronics Firms, Journal of Product Innovation Management, 11(5): 418-432.

20. Montoya-Weiss, M.M. and Calantone, R. (1994). Determinants of New Product performance: A Review and Meta Analysis, Journal of Product Innovation Management, 11(5): 397-417.

21. Allen, T.J. (1977). Managing the Flow of Technology: Technology Transfer and the Dissemination of Technological Information within the R\&D Organization, Massachusetts: MIT Press.

22. Allen, T.J. (2000). Architecture and Communication Among Product Development Engineers, In: Proceedings of the 2000 IEEE Engineering Management Society, EMS 2000, Albuquerque, New Mexico.

23. Smith, R.P. and Eppinger, S.D. (1997). A Predictive Model of Sequential Iteration in Engineering Design, Management Science, 43(8): 1104-1120.

24. Loch, C.H. and Terwiesch, C. (1998). Communication and Uncertainty in Concurrent Engineering, Management Science, 44(8): 1032-1048.

25. Eckert, C.M. and Stacey, M.K. (2001). Dimensions of Communication in Design, International Conference on Engineering Design (ICED), Glasgow.

26. Eckert, C.M., Clarkson, P.J. and Stacey, M.K. (2001). Information Flow in Engineering Companies: Problems and their Causes, International Conference on Engineering Design (ICED), Glasgow.

27. Hales, C. (1987). Analysis of the Engineering Design Process in an Industrial Context, Ph.D. Dissertation, University of Cambridge, Cambridge.

28. Hales, C. and Gooch, S. (2004). Managing Engineering Design, 2nd edn, London, New York, Berlin: Springer.

29. Badke-Schaub, P. and Frankenberger, E. (1999). Analysis of Design Projects, Design Studies, 20(5): 465-480.

30. Badke-Schaub, P. and Frankenberger, E. (2004). Management Kritischer Situationen. Produktentwicklung Erfolgreich Gestalten. Berlin, Heidelberg: Springer.

31. Roberts, T.L., Cheney, P.H. and Sweeney, P.D. (2002). Project Characteristics and Group Communication: An Investigation, IEEE Transactions on Professional Communication, 45(2): 84-98.

32. Chiu, M.-L. (2002). An Organizational View of Design Communication in Design Collaboration, Design Studies, 23(2): 187-210.

33. Tiernan, S.D., Flood, P.C. and Murphy, E.P. (2002). Employee Reactions to Flattening Organizational Structures, European Journal of Work and Organizational Psychology, 11(1): 47-67.

34. Luhmann, N. (1995). Social Systems, Stanford: Stanford University Press. 
35. Jonas, W. (1994). Design - System - Theorie: überlegungen zu einem systemtheoretischen Modell von Design-Theorie. Essen, p. 299.

36. Pulm, U. (2004). A System-Theoretic Treatment of Product Development (Translated from: Eine systemtheoretische Betrachtung der Produktentwicklung, Ph.D. Dissertation, Lehrstuhl für Produktentwicklung), Technische Universität München, München.

37. Maier, A.M., Eckert, C.M. and Clarkson, P.J. (2005). A Meta-model for Communication in Engineering Design, CoDesign: International Journal of CoCreation in Design and the Arts, 1(4): 243-254.

38. Spencer, H. (1965). The Principles of Sociology, In: Parsons (ed.), Theories of Society, pp. 139-143, New York: Free Press.

39. Busseri, M.A. and Palmer, J.M. (2000). Improving Teamwork: The Effect of Self-assessment on Construction Design Teams, Design Studies, 21(3): 223-238.

40. Dörner, D. (1996). The Logic of Failure, New York: Metropolitan Books.

41. Blickensderfer, E., Cannon-Bowers, J.A. and Salas, E. (1997). Theoretical Bases for Team Selfcorrection: Fostering Shared Mental Models, Advances in Interdisciplinary Studies of Work Teams, 4: 249-279.

42. Valkenburg, R.C. (2000). The Reflective Practice in Product Design Teams to Assess Product Design Capability, Ph.D. Dissertation, Delft University of Technology, Delft.

43. Stempfle, J. and Badke-Schaub, P. (2002). Thinking in Design Teams - an Analysis of Team Communication, Design Studies, 23(5): 273-296.

44. Badke-Schaub, P., Wallmeier, S. and Dörner, D. (1999). Training for Designers: A Way to Reflect Design Processes and Cope with Critical Situations in Order to Increase Efficiency, In: International Conference on Engineering Design (ICED), Munich.

45. Crosby, P.B. (1979). Quality is Free, New York: McGraw Hill.

46. Paulk, M.C., Curtis, B., Chrissis, M. and Weber, C.V. (1993). Capability Maturity Model $^{\mathrm{SM}}$ for Software, Version 1.1 Pittsburgh, Pennsylvania, Report CMU/ SEI-93-TR-024 ESC-TR-93-177.

47. Chiesa, V., Coughlan, P. and Voss, C. (1996). Development of a Technical Innovation Audit, Journal of Product Innovation Management, 13(2): 105-136.

48. Chrissis, M.B., Konrad, M. and Shrum, S. (2003). CMMI. Guidelines for Process Integration and Product Improvement, Boston: Addison-Wesley.

49. Moultrie, J. (2004). Development of a Design Audit Tool, Ph.D. Dissertation, University of Cambridge, Cambridge.

50. Austin, S., Baldwin, A., Hammond, J., Murray, M., Root, D., Thomson, D. and Thorpe, A. (2001). Design Chains. A Handbook for Integrated Collaborative Design. Loughborough: Amec.

51. Argyris, C. and Schön, D. (1978). Organizational Learning: A Theory of Action Perspective, Reading (Mass): Addison Wesley.

52. Brown, D.C. (1996). Routineness Revisited. In: Waldron, M. and Waldron, K. (eds), Mechanical Design: Theory and Methodology, pp. 195-208, New York: Springer Verlag.

53. Bolboaca, S.-D. and Jäntschi, L. (2006). Pearson versus Spearman, Kendall's Tau Correlation Analysis on Structure-Activity Relationships of Biologic Active Compounds, Leonardo Journal of Sciences, 9: 179-200.
54. Brosius, F. (1998). SPSS 8.0. Professionelle Statistik unter Windows. Bonn: mitp, 1998.

55. Brown, B.L. Correlations. Available: http://www.gpc.edu/ $\sim$ bbrown/psyc1501/methods/correlations.htm, 2006.

56. Lindemann, U., Maurer, M. and Kreimeyer, M. (2005). Intelligent Strategies for Structuring Products, In: Clarkson, J.P. (ed.), Engineering Design - Theory and Practice, pp. 106-115, Cambridge: Engineering Design Centre.

57. Boardman, J. and Sauser, B. (2006). System of Systems the Meaning of System of Systems Engineering, 2006 IEEE/SMC International Conference, 24-26 April.

58. Eichinger, M., Maurer, M., Pulm, U. and Lindemann, U. (2006). Extending Design Structure Matrices and Domain Mapping Matrices by Multiple Design Structure Matrices, In: Proceedings of ASME ESDA 2006, Torino, Italy.

59. Colarelli, S.M. and Boos, A.L. (1992). Sociometric and Ability-based Assignment to Work Groups: Some Implications for Personnel Selection, Journal of Organizational Behavior, 13(2): 187-196.

60. Vianen, A.E.M.v. and Dreu, C.K.W.D. (2001). Personality in Teams: Its Relationship to Social Cohesion, Task Cohesion, and Team Performance, European Journal of Work and Organizational Psychology, 10(2): 97-120.

61. Perry, M. and Sanderson, D. (1998). Coordinating Joint Design Work: the Role of Communication and Artefacts, Design Studies, 19(3): 273-288.

62. Moenaert, R.K., Caeldries, F., Lievens, A. and Wauters, E. (2000). Communication Flows in International Product Innovation Teams, Journal of Product Innovation Management, 17(1): 360-377.

63. Ahuja, M.K., Galletta, D.F. and Carley, K.M. (2003). Individual Centrality and Performance in Virtual R\&D Groups: An Empirical Study, Management Science, 49(1): 21-38.

64. Krackhardt, D. and Stern, R.N. (1998). Informal Networks and Organizational Crises: An Experimental Simulation, Social Psychology Quarterly, 51(2): 123-140.

65. Wong, P.S.P. and Cheung, S.O. (2005). Structural Equation Model of Trust and Partnering Success, Journal of Management in Engineering, 21(2): 70-80.

66. Ng, K.-Y. and Chua, R.Y.J. (2006). Do I Contribute More When I Trust More? Differential Effects of Cognition and Affected-based Trust, Management and Organization Review, 2(1): 43-66.

67. Bstieler, L. (2006). Trust Formation in Collaborative New Product Development, Journal of Product Innovation Management, 23(1): 56-72.

68. Eckert, C.M., Stacey, M.K. and Earl, C.F. (2003). Ambiguity is a Double-edged Sword: Similarity References in Communication, In: ICED03, 14th International Conference of Engineering Design, Stockholm, Sweden.

69. Kuhn, T. and Nelson, N. (2002). Reengineering Identity, Management Communication Quarterly, 16(1): 5-38.

70. Susman, G.I., Gray, B.L., Perry, J. and Blair, C.E. (2003). Recognition and Reconciliation of Differences in Interpretation of Misalignments When Collaborative Technologies are Introduced into New Product Development Teams, Journal of Engineering and Technology Management, 20(1): 141-159.

71. Newman, R.A. (1999). Issues in Defining Human Roles and Interactions in Systems, Systems Engineering, 2(3): $143-155$. 
72. Thamhain, J.J. (2003). Managing Innovative R\&D Teams, $R \& D$ Management, 33(3): 297-311.

73. Ayas, K. (1997). Integrating Corporate Learning with Project Management, International Journal of Production Economics, 51(1): 59-67.

74. Meijer, B.R. (2006). Organization Structures of Dealing with Complexity, Ph.D. Dissertation, Management Science, Delft: Delft University of Technology.

75. Murphy, G.L. and Medin, D.L. (1985). The Role of Theories in Conceptual Coherence, Psychological Review, 92(3).

76. Keil, F.C. (2003). Categorization, Causation and the Limits of Understanding, Language and Cognitive Processes, 18(5/6): 663-692.

\section{Anja M. Maier}

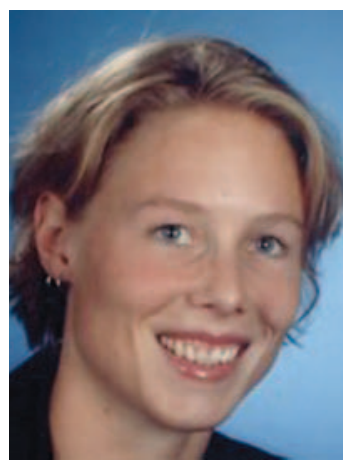

Anja M. Maier graduated form the University of Münster and University of Toronto with a Masters degree in Political Science, Communication Science and Philosophy in 2002 and is now a Research Associate at the Engineering Design Centre (EDC) of the University of Cambridge, where she completed her doctoral degree on communication in engineering design.

Her interests are in the areas of design process improvement, collaborative designing, communication in design, system theory, system dynamics, performance assessment systems and philosophy of design. In particular, she is focusing on design as communication between the designers and designers via the product. She has published a number of conference and journal papers.

Ms. Maier has received a selected paper award at the Design Conference 2006 in Dubrovnik for a paper that will soon be published in the Journal of Engineering Design. She has professional experience in the field of information technology and is a fellow of the Cambridge Philosophical Society.

\section{Matthias Kreimeyer}

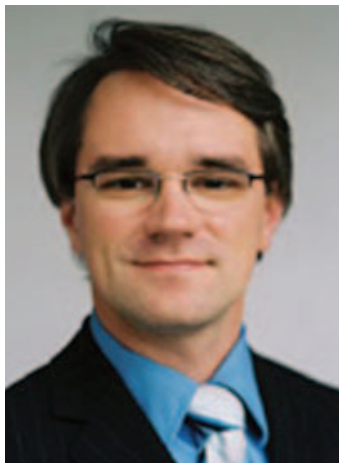

Matthias Kreimeyer, born in Hannover, Germany, in 1976, completed his MSc. degree as mechanical engineer at the German universities of Hannover and Munich in 2004. He also graduated as Ingénieur ECP from the Ecole Centrale Paris in 2003, finishing a double degree in general engineering.
He has gathered experience in industry working for several major automotive manufacturers in Europe, Asia and Northern America. Currently, he works as a Research Assistant at the Institute of Product Development at the Technische Universität München, Germany. He has published a number of papers on collaboration and concurrent design processes, which are the focus of his research interest. His work also focuses on methods for complexity management.

Mr. Kreimeyer has received a selected paper award at the Design Conference 2006 in Dubrovnik for a paper that will soon be published in the Journal of Engineering Design.

\section{Clemens Hepperle}

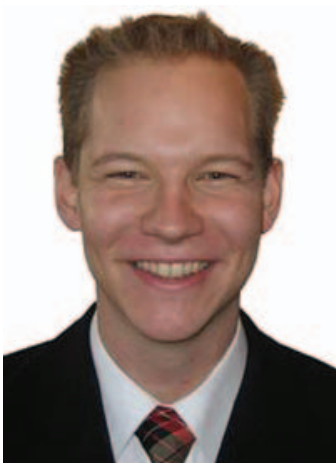

Clemens Hepperle born in Innsbruck, Austria, in 1980, graduated as mechanical engineer at the Technische Universität München in 2006. A major part of his studies in mechanical engineering focused on systematic product development.

He completed his Diploma Thesis at the Engineering Design Centre at the University of Cambridge (UK), dealing with communication factors in collaborative design. He now works as a Research Assistant at the Institute for Product Development at the Technische Universität München, Germany.

\section{Claudia M. Eckert}

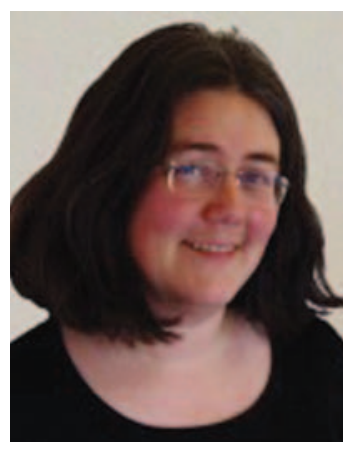

Claudia M. Eckert is a Senior Research Associate and Assistant Director of the Engineering Design Centre at the University of Cambridge. Her background is in mathematics, philosophy, and artificial intelligence.

She is interested in various aspects of design process improvement, in particular process planning, change predication, and communication in design. She is currently working on comparisons between design practice in different domains.

Dr. Eckert has published over 100 conference and journal papers and co-edited a book on design process improvement. She is a member of the editorial board of Design Studies. 


\section{Udo Lindemann}

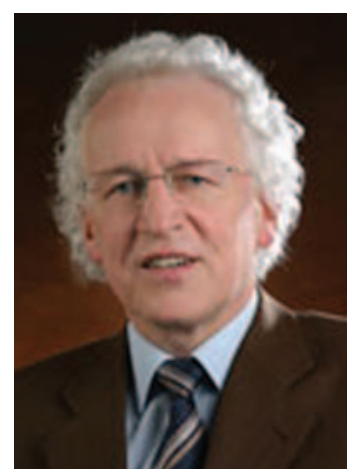

Udo Lindemann born in 1948, graduated as mechanical engineer from the University of Hannover, Germany. After starting his doctorate there, he finished his work on 'A system's perspective on the design process with special regard of the production costs during shape definition' at the Technische Universität München in 1979.

During the following years, he worked in management positions in product design, production, and testing technology for Renk AG, Augsburg in Germany. After 1992, he was CEO of MAN Miller Druckmaschinen $\mathrm{GmbH}$. At the same time, he was product manager for small sheet fed printing units at MAN Roland AG.

Since 1995, he is full professor at the Technische Universität München and Head of the Institute of Product Development. Prof Dr Lindemann is active in a number of professional societies as for example Berliner Kreis, WGMK, VDI and The Design Society.

\section{P. John Clarkson}

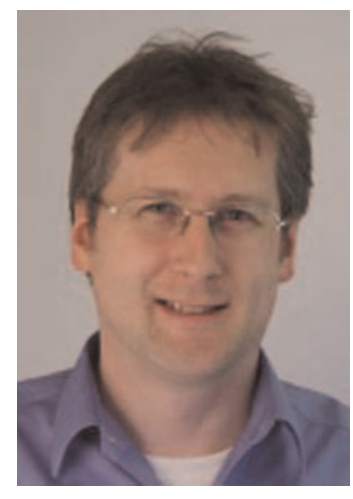

John Clarkson is Professor of Engineering Design and Director of the Engineering Design Centre at the University of Cambridge. His research interests are in the general area of engineering design, in particular the development of design methodologies to address specific design issues.

In addition to publishing over 400 papers in the past ten years he has written a number of practitioner workbooks on medical equipment design and inclusive design. Prof. Clarkson is a Chartered Engineer, a Fellow of the Institute of Engineering and Technology, and a Member of the American Society of Mechanical Engineers and the Design Society.

Prof Clarkson is a Chartered Engineer, a Member of the Institute of Electrical Engineers, Associate Editor of the ASME Journal of Mechanical Design and on the editorial board of the Journal of Engineering Design. 
Exploration of Correlations between Factors Influencing Communication

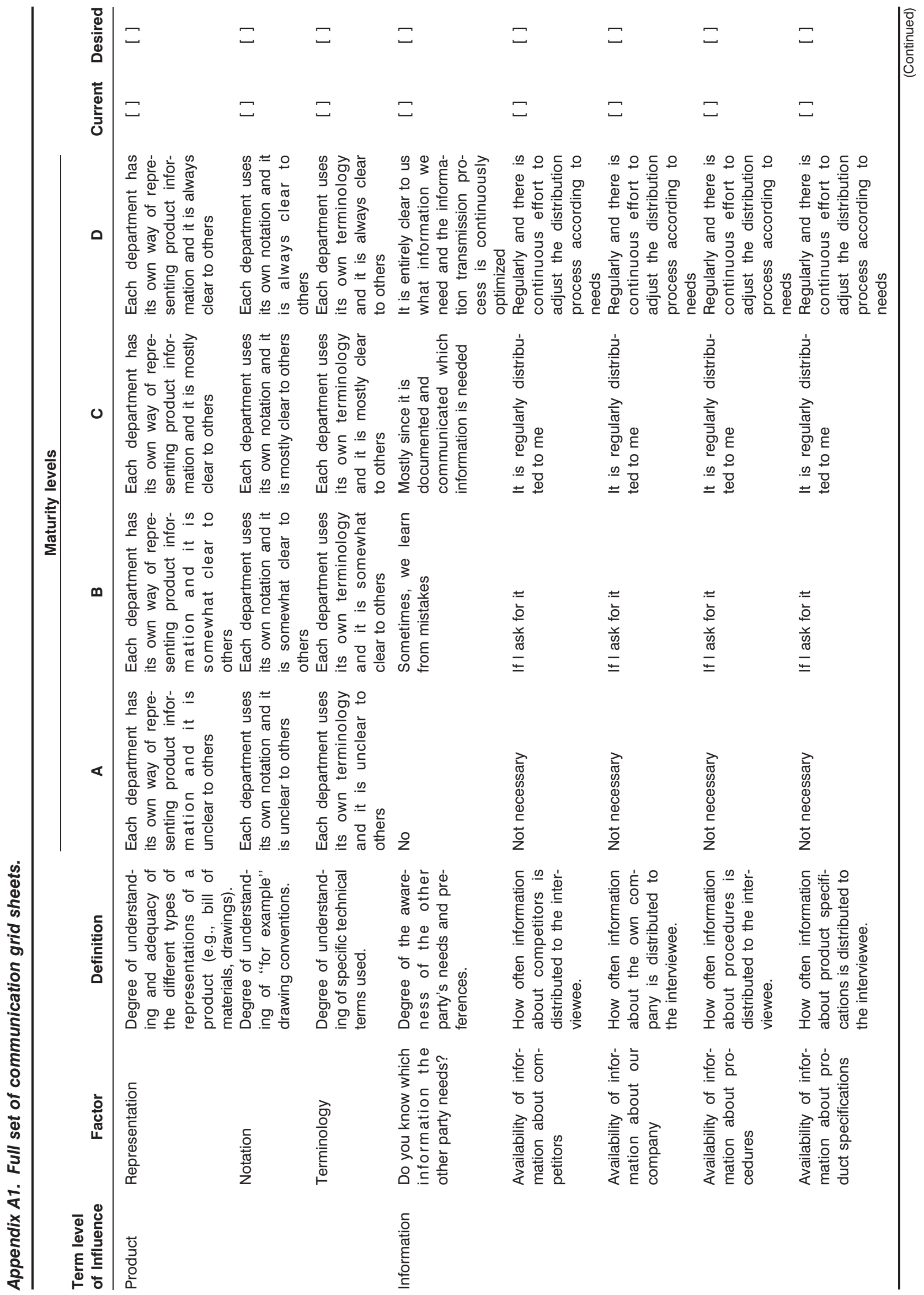


A. M. Maier et AL.

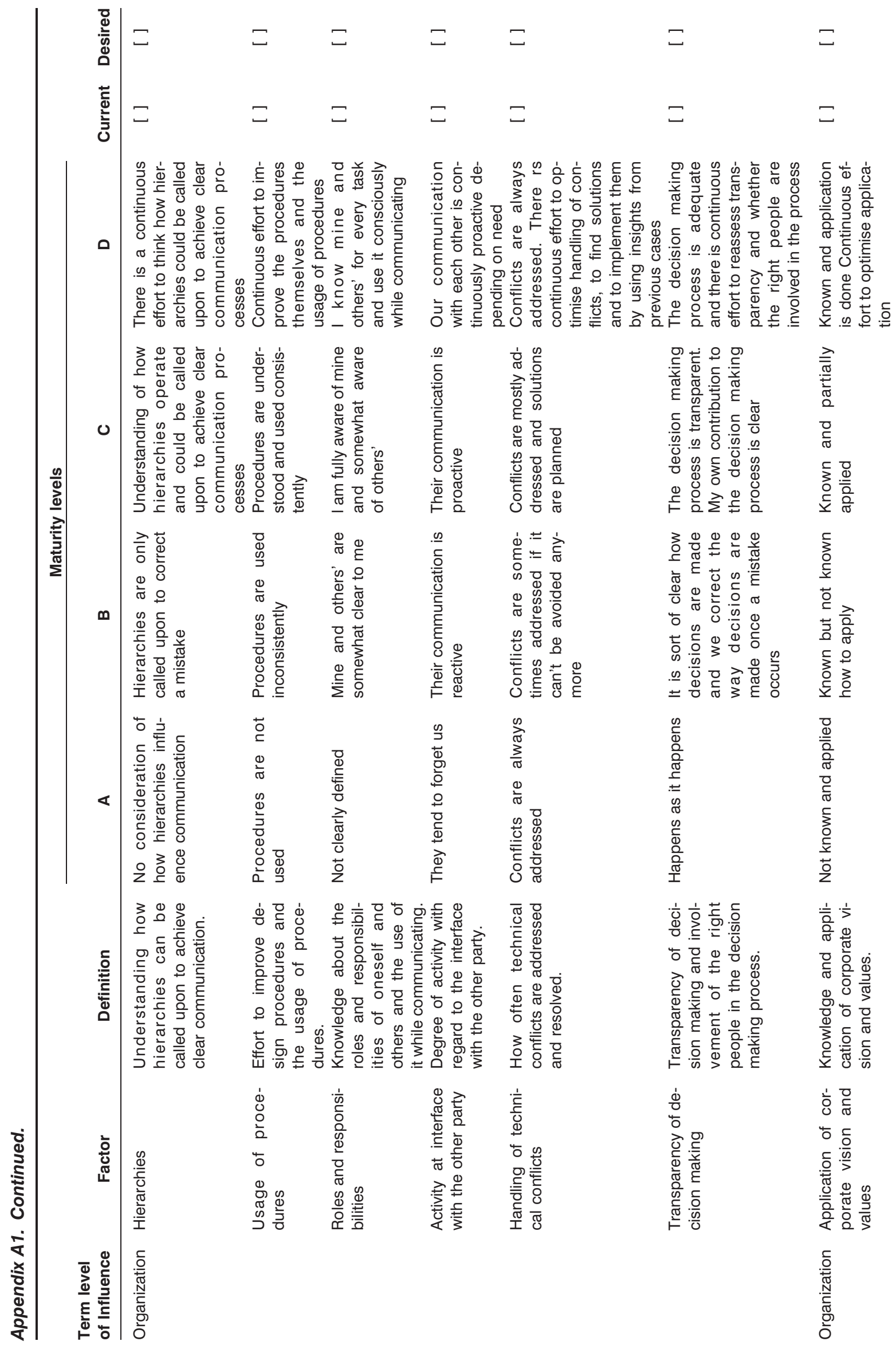




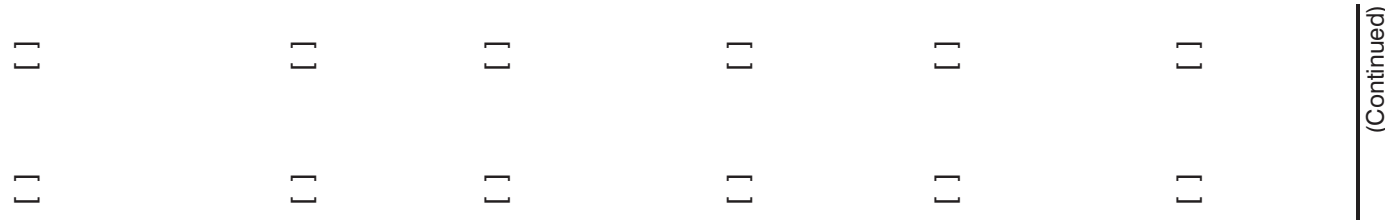

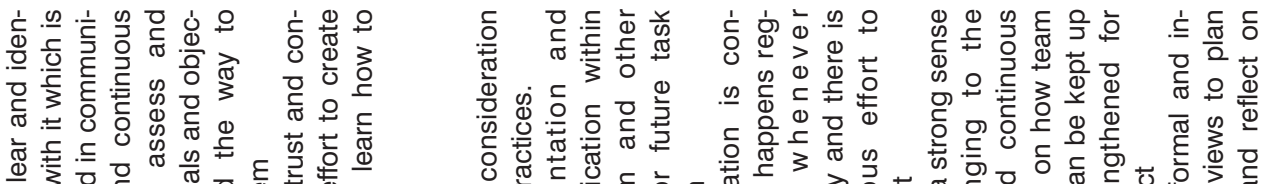

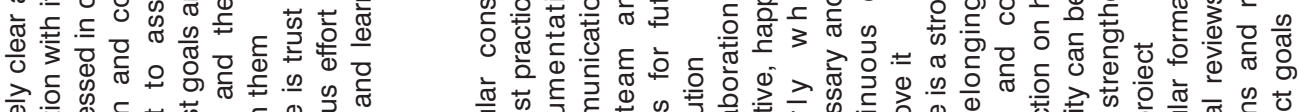

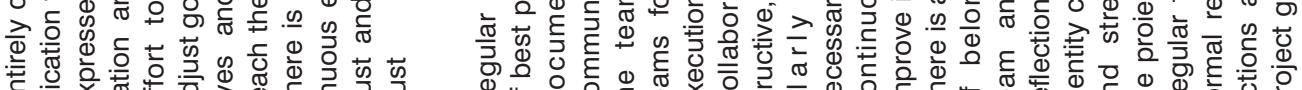

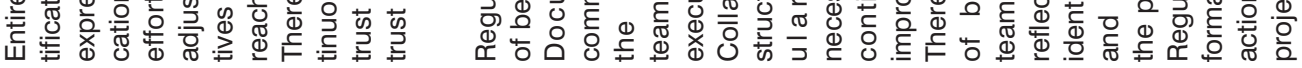
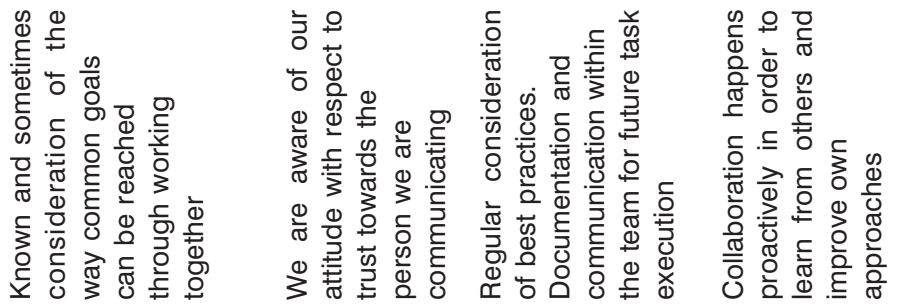

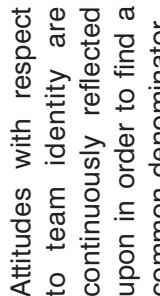

ㅎํㅇ $\frac{\pi}{2}$

离㐫

व $\frac{0}{\underline{E}}$

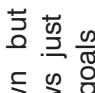

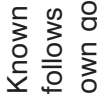

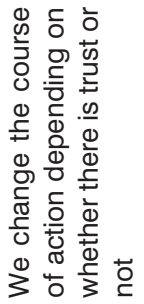

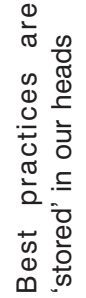

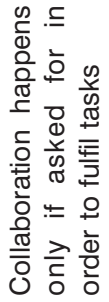

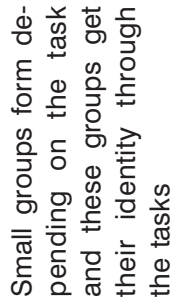

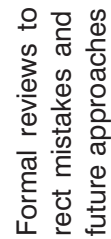

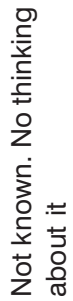

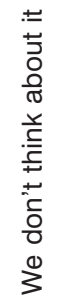

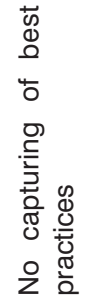

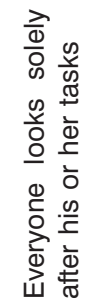

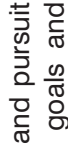

סु

\section{뚱요}

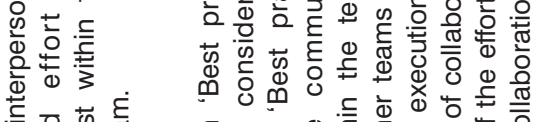

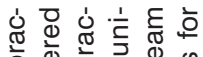

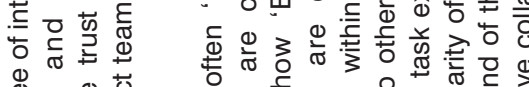

过的兽

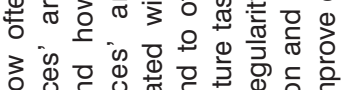

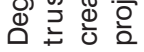

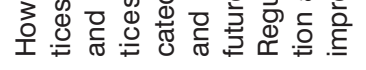

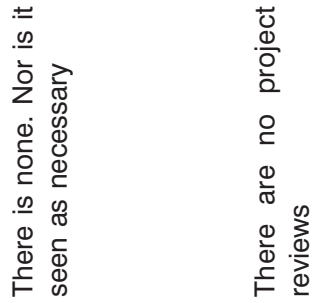

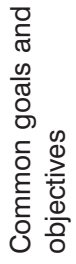

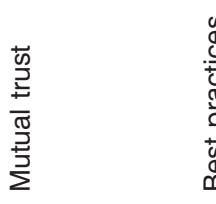

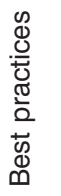

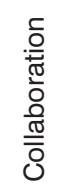

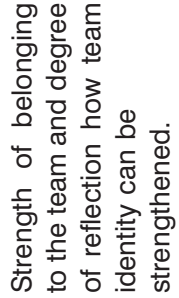

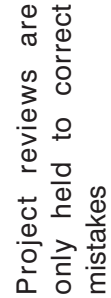

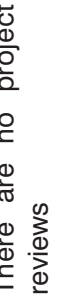
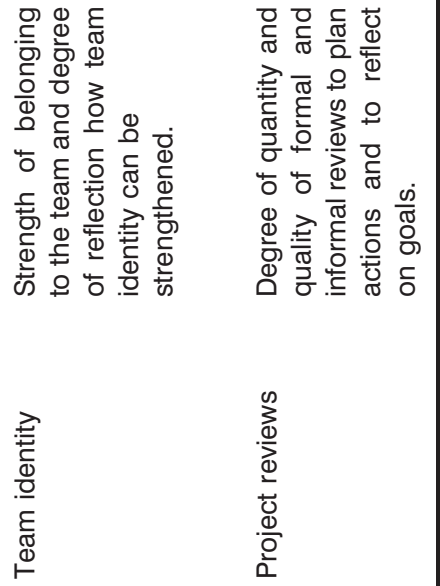

$\frac{\sum_{0}^{0}}{\frac{0}{20}}$ 
A. M. MAier et AL.

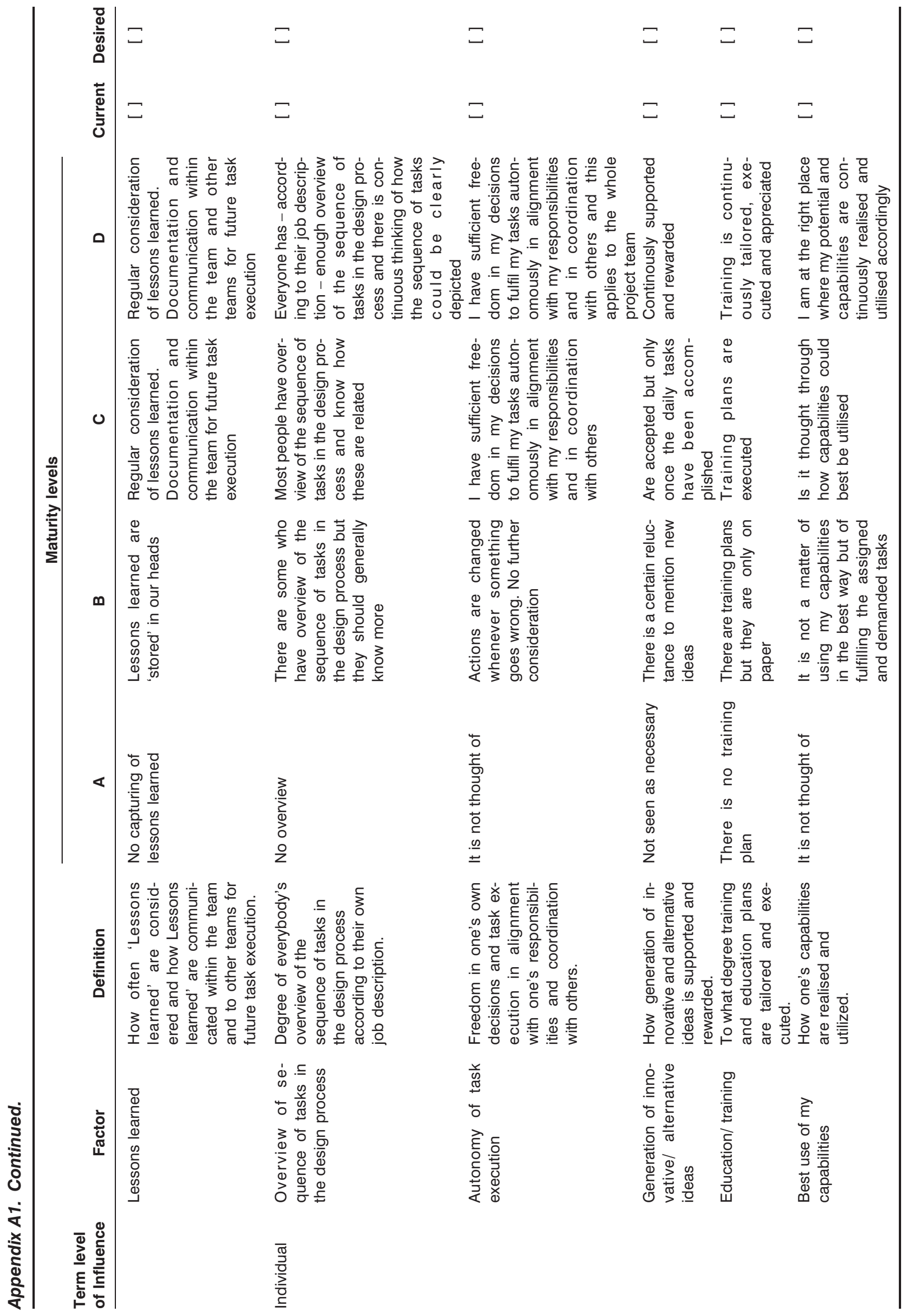




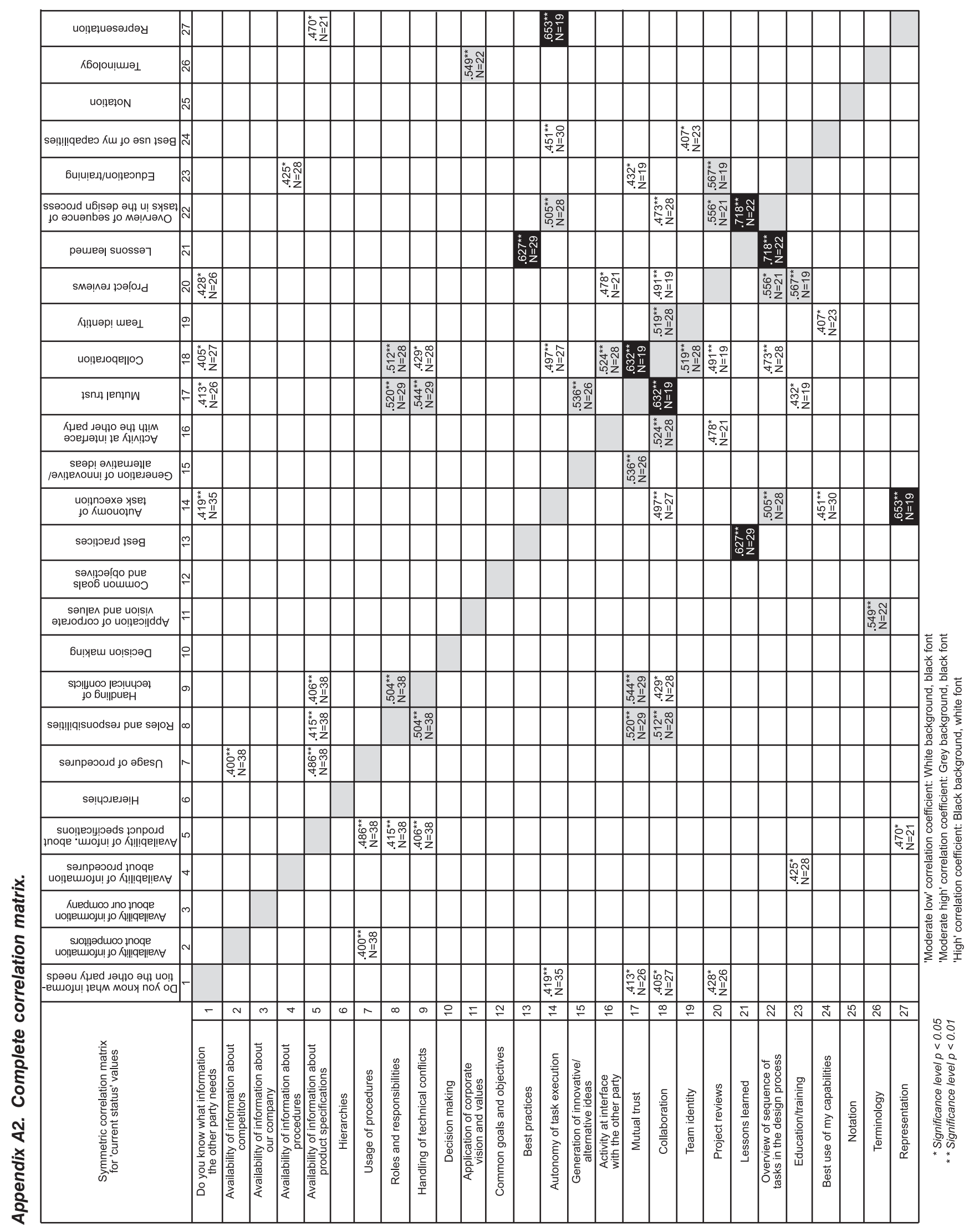

